\title{
Ethnic and gender differences in perceptions of mortality risk in a Canadian urban centre
}

\author{
Gilat L Grunau' \\ Pamela A Ratner ${ }^{1,2}$ \\ Shahadut Hossain' \\ 'NEXUS; ${ }^{2}$ School of Nursing, \\ University of British Columbia, \\ Vancouver, Canada; University \\ of British Columbia, Vancouver, \\ Canada
}

\begin{abstract}
Background: Women reportedly do not perceive heart disease (HD) as a major threat to their health; however, men's perceptions are rarely studied.

Purpose: We explored gender and ethnic differences in risk perception of HD mortality.

Methods: The survey was completed by 976 people $40+$ years of age, in metropolitan Vancouver, Canada.

Results: Men, compared with women, were more likely not to know the answer to a question about whether HD is the most common cause of death for women; however, women were more likely not to know the answer to a question about whether HD is the most common cause of death for men. Chinese-Canadian and South Asian-Canadian participants were more likely than participants of other ethnic groups not to know the answer to either question, and the Chinese-Canadian participants were more likely to disagree that HD is the most common cause of death for women.

Conclusion: There is a need to educate the Chinese-Canadian and South Asian-Canadian communities about HD as a first step in promoting health behavior change. Men and women must be educated about the other gender's risk of HD because all adults play integral roles in making decisions about the prevention of and early intervention for HD.
\end{abstract}

Keywords: risk assessment, heart disease, mortality, gender, ethnic groups

\section{Background}

Cardiovascular disease (CVD), which is a group of disorders of the heart and blood vessels that include coronary heart disease, cerebrovascular disease, peripheral arterial disease, rheumatic heart disease, congenital heart disease, deep vein thrombosis, and pulmonary embolism, is the leading cause of death globally and is projected to remain the leading cause of death (WHO 2008).

According to the American Heart Association, the number of CVD deaths for American women since 1984 has exceeded that of men. In the United States in 2004, all CVDs combined claimed the lives of 459,096 women (compared with 410,628 men), while all forms of cancer combined to kill 267,058 women. In comparison, breast cancer claimed the lives of 40,954 women and lung cancer claimed 68,461 (AHA 2008). In Canada, there is a similar pattern. In 2004, CVD claimed the lives of 36,491 women, compared with 35,847 men (a subset of CVD, specifically diseases of the heart, claimed 24,924 women's lives and 27,076 men's lives), while all forms of cancer combined were responsible for 31,791 deaths in women. Breast cancer claimed the lives of 4,964 women and lung cancer claimed 7,517 Canadian women's lives (Statistics Canada 2004b).

Despite these compelling numbers, researchers have found that women do not consider heart disease to be a major threat to their health. A survey in the USA, which included 3,000 women in 1993 (Pilote and Hlatky 1995), found that twice as many women reported being worried about breast cancer as reported being worried 
about heart disease (59\% vs 29\%). When asked what illness they feared most, three times as many feared breast cancer as feared heart disease (48\% vs 16\%). In general, women perceived their risk of heart disease to be low and their risk of breast cancer to be high. In another survey of women in the USA (Mosca et al 2005) in 2005, only 8\% of the respondents identified heart disease and stroke as their greatest health concerns, whereas $61 \%$ of women noted cancer as women's greatest health problem. When identifying the leading cause of death, $31 \%$ of all respondents reported heart disease or stroke and 50\% reported cancer. In a survey of college students in the USA, respondents believed that heart disease risk is lower for women than for men, and a majority of students incorrectly believed that breast cancer is a more significant health concern for women than is heart disease. Although the largest number of both male and female respondents indicated that cancer was their greatest health risk, the women were more likely to provide this response than were men. Approximately $49 \%$ of the women and $37 \%$ of the men believed that cancer was their greatest health risk. When focusing on different ethnic groups, the researchers found that cancer was identified as the greatest health risk by the majority of white, Hispanic, and African American respondents, but the majority of Asian and Native American respondents indicated that heart disease was their greatest health risk. Sixty-nine percent of the sample indicated that heart disease was the most significant cause of death for men, but $67 \%$ believed that cancer was the leading cause of death for women. Heart disease was recognized as the most common cause of death for women by only $25 \%$ of the respondents (Collins et al 2004). Similarly, another survey, also conducted in the USA (Legato et al 1997), found that $74 \%$ of all surveyed women rated themselves as fairly or very knowledgeable about women's health issues, yet $44 \%$ considered themselves somewhat or very unlikely to have a heart attack at some time in their lives. Fifty-eight percent believed that they were as or more likely to die of breast cancer than of coronary artery disease (CAD). The researchers also examined the counseling the women reportedly received from their doctors and concluded that a surprisingly large number of women are not counseled at all or are inadequately counseled about their susceptibility to CAD.

Despite these findings, there has been an increase in CVD awareness over the past decade. Miller and Kollauf (2002) traced the evolution of information about women and heart disease, and found that during the 1960s, articles and programs focused on how women could take care of their husbands' hearts. The 1980s brought a dramatic surge in literature about women's health, specifically about their risk for heart disease. They concluded that despite the growing body of literature, more information and educational programs are needed to increase public awareness of cardiac warning signs and symptoms in women. These findings are supported by Hammond and colleagues (2007) who conducted a literature review of women's risk perception of heart disease. They found that until the late 1980s, CVD was perceived as a disease that primarily affected men, and few large clinical trials recruited women. This resulted in a lack of data documenting the relationships between known risk factors and gender. A few studies have shown that awareness of heart disease in women has increased over the years. In a telephone survey of women conducted in 2003 in the USA (Mosca et al 2004), researchers found that $46 \%$ of the respondents spontaneously identified heart disease as the leading cause of death in women, up from 30\% in 1997 and $34 \%$ in 2000 . Consistent with this, the percentage of women that cited cancer as the leading cause of death had significantly decreased. Black, Hispanic, and younger women ( $<45$-years-old) had poorer awareness of heart disease as their leading cause of death compared with white and older women. In a follow-up survey in 2006, awareness of heart disease as the leading cause of death among women was $57 \%$, significantly higher than in previous surveys. Awareness was poorer among black and Hispanic women compared with white women (31\% and 29\%, respectively, vs 68\%); and these racial/ethnic differences have not changed appreciably over time. The researchers concluded that CVD awareness has increased significantly among American women over the past decade, yet the racial/ethnic gap in awareness has not narrowed. Although awareness of CVD has increased, a significant gap between perceived and actual risk of CVD remains (Mosca et al 2004).

The researchers who have studied risk perception and awareness of heart disease in women have almost exclusively studied women alone. It is also important to include men in these surveys, however, because their perceptions may affect women's health behavior at the individual level, and their knowledge influences policy decisions. Public perceptions of risk influence various organizations' (including governments') agendas and priority setting (Slovic 2001). In addition, most of the studies investigating ethnic differences in risk perception of heart disease and cancer were conducted in the United States where the ethnic diversity is very different from that found in Canada. The purpose of this study was to investigate gender and ethnic differences in risk perception of heart disease mortality in women and men in a Canadian 
urban center. This study was part of a larger study aimed to identify the relationship between sociodemographic, clinical, cognitive, psychological, and social factors and delay in treatment seeking for cardiac symptoms, and to explicate the role that gender and ethnicity play in modifying these risk factors.

The specific focus of this paper is on gender and ethnic differences with respect to risk perception of heart disease as a leading cause of death in men and women.

\section{Methods}

\section{Sample, data collection, and questionnaire}

This study used data collected as part of a larger study which is described in detail elsewhere (Ratner et al 2006, 2008). In general, a random sample of men and women $(n=3,419)$, 40 years of age and older, living in metropolitan Vancouver, British Columbia (BC), Canada was selected for a telephone survey. The questionnaire was administered in four languages (English, Punjabi, Mandarin, and Cantonese) to ensure representation of the two largest "visible minority" communities in Vancouver (Chinese and South Asian). These communities make up $70 \%$ of all visible minority groups (Statistics Canada 2004a).

Participants were classified as "Chinese" if they met the following two criteria: (a) they were born in a country other than Canada and (b) they spoke Chinese as their first language or self-identified as Chinese. Similarly, participants were classified as "South Asian" if they met these two criteria: (a) they were immigrants to Canada and (b) they spoke Punjabi or Hindi as their first language, or self-identified as Punjabi.

The remaining respondents were classified as: born in Canada or not born in Canada (but not Chinese or South Asian). Three cases were excluded from the analyses; they functioned entirely in English, were born in Canada, spoke Chinese as their first language, and identified as Chinese. Given that none of the other participants born in Canada indicated that they were Chinese or spoke Chinese as their first language, we concluded that these few individuals did not fit into the categorization scheme and were therefore excluded.

The sample was obtained from the population-based BC Ministry of Health Services, Client Registry Database. The registry includes the name, gender, birth date, and contact information of all insured residents (Krenten-Boaretto et al 2003). To be listed, residents who have lived in the province for at least three months must apply for the Medical Services Plan, which insures all medically required services provided by physicians and other healthcare practitioners, laboratory services, and diagnostic procedures; military and Royal Canadian Mounted Police personnel are excluded.

The questionnaire included 71 questions, and of those, 4 questions were the focus of this study:

1. Heart disease is the most common cause of death in women in Canada (True or False?)

2. If false, what do you think is the most common cause of death in women? (Open ended, no response options provided)

3. Heart disease is the most common cause of death in men in Canada (True or False?)

4. If false, what do you think is the most common cause of death in men? (Open ended, no response options provided)

Approval for accessing the list and conducting the study was received from the BC Ministry of Health's Confidentiality Agreement: Security Provisions for Personal Information in Individual Identifiable Form and from the University of British Columbia's Behavioural Research Ethics Board.

\section{Analysis}

The statistical packages SPSS (SPSS Inc., Chicago, IL, USA) and S-Plus (Insightful Corp, Seattle, WA, USA) were used for data analysis. Differences in proportions were tested with Chi-square. Multinomial logistic regression was used to assess the relationships between the predictors and the outcome variable for Questions 1 and 3 (with the three categories for the outcome variable being: True, False, Don't know). Independent variables in the regression model included: gender, age, ethnicity, income, education, and history of acute myocardial infarction (AMI), either personally, in the family or among friends.

Nineteen percent of the participants did not disclose their household income; therefore, to reduce bias, multiple imputations of values for missing data were used. A set of covariates and other variables predictive of those covariates were used to impute five complete sets of data. Multinomial logistic regression analysis was completed, as described above, for each dataset and the estimated coefficients were averaged across the five datasets. We defined $p<0.05$ as significant.

\section{Results}

Of the 3,419 names from the client registry, 976 people completed the survey, and 759 refused to participate. The remaining 1,684 people were found to be ineligible or could not be contacted (39\% were "wrong" or fax 
numbers; $26 \%$ were numbers not in service; $25 \%$ could not be contacted; $5 \%$ no longer lived in the sampling area; $4 \%$ spoke languages other than those provided; and 1\% had died); the minimum response rate was $28.5 \%$ (defined as the number of completed interviews divided by the number of interviews plus the number of noninterviews (refusals) plus all cases of unknown eligibility) (Mosca et al 2005). The maximum response rate was $56.3 \%$ (defined as the number of completed interviews divided by the number of interviews plus the refusals; this eliminated those who had died, were known to not meet the eligibility criteria, and those cases with no contact for whom eligibility could not be determined).

The interview language chosen by the respondents was as follows: $85.1 \%$ completed the survey in English, 11.5\% in Chinese, and 3.4\% in Punjabi. The age of the participants ranged from 40 (by inclusion criterion) to 89 years with a mean of 55.5 years $(\mathrm{SD}=11.1)$. For other characteristics see Table 1. For sample characteristics by gender-specific ethnic status see Ratner and colleagues (2006).

\section{Univariate analysis}

When asked whether heart disease is the most common cause of death for women, $52.4 \%$ of the sample responded 'True'; when asked whether heart disease is the most common cause of death for men, $74.7 \%$ responded 'True'.

\section{Gender differences}

Statistically significant differences were found between men's and women's responses to the question, "Heart disease is the most common cause of death in women in Canada" $(p=0.036)$. No statistically significant differences were found between men's and women's responses to the question, "Heart disease is the most common cause of death in men in Canada" (see Table 2).

There were statistically significant differences $(p=0.003)$ between the men's and women's reported common cause of death for women, if heart disease was considered to be false (Question 2). Almost 17\% of the women in the sample reported that the leading cause of death was cancer (unspecified); 16.1\% believed that breast cancer was the most common cause, and none mentioned lung cancer. For the male respondents: $17.2 \%$ reported the most common cause of death to be breast cancer, $15.1 \%$ believed it was cancer (unspecified), and $1.9 \%$ reported that it was lung cancer.

No statistically significant gender differences were found for the reported most common cause of death for men if heart disease was considered false (Question 4). Almost $8 \%$ of the
Table I Sample characteristics

\begin{tabular}{ll}
\hline Characteristic & $(\mathbf{n}=976)$ \\
\hline Age (mean [SD] - years) & $55.5(11.1)$ \\
Gender (n [\%]) & \\
Male & $425(43.5)$ \\
Female & $548(56.1)$ \\
Missing & $3(0.3)$ \\
Ethnicity (n (\%)) & \\
Born in Canada & $536(54.9)$ \\
Not born in Canada (Not Chinese/South Asian) & $221(22.6)$ \\
South Asian (not born in Canada) & $67(6.9)$ \\
Chinese (not born in Canada) & $149(15.3)$ \\
Unclassified & $3(0.3)$ \\
Total household income (n (\%)) & \\
$\$ 0-\$ 19,999$ & $77(7.9)$ \\
$\$ 20,000-\$ 39,999$ & $150(15.4)$ \\
$\$ 40,000-\$ 59,999$ & $168(17.1)$ \\
$\$ 60,000-\$ 79,999$ & $118(12.1)$ \\
$\$ 80,000-\$ 99,999$ & $107(11.0)$ \\
$\$ 100,000+$ & $171(17.5)$ \\
Missing & $185(19.0)$ \\
Education (n [\%]) & $693(71.0)$ \\
$<$ High school & $9(0.9)$ \\
High school & $92(9.4)$ \\
College/diploma/certificate/incomplete & $243(24.9)$ \\
university & \\
Baccalaureate or higher & $2942(35.0)$ \\
Missing & $5(0.5)$ \\
AMI history in self, family or friend (n [\%]) & \\
Yes & \\
No & \\
\hline
\end{tabular}

sample mentioned cancer (unspecified) as the leading cause of death, $3.7 \%$ believed that it was prostate cancer, and $1.5 \%$ mentioned lung cancer (see Table 3 ).

\section{Ethnicity}

There were significant differences between the ethnic groups' responses to all the questions. Most of the Chinese subsample (63.1\%) answered 'False' to Question 1 compared with $32.4 \%$ to $39.4 \%$ of the other ethnic groups. Also, a large proportion of the Chinese and the South Asian subsamples answered 'Don't know' to Question 1 (14.1\% and 22.4\%, respectively) compared with the other subsamples. With regard to Question 3, a large proportion of the Chinese and South Asian subsamples answered 'Don't know' 


\begin{tabular}{|c|c|c|c|}
\hline & $\begin{array}{l}\text { Men }(n=425) \\
n(\% \text { of men) }\end{array}$ & $\begin{array}{l}\text { Women }(n=548) \\
n(\% \text { of women) }\end{array}$ & $\begin{array}{l}\text { Total }(n=973)^{\phi} \\
n(\% \text { of total })\end{array}$ \\
\hline \multicolumn{4}{|c|}{$\begin{array}{l}\text { Question I: Heart disease most } \\
\text { common cause of death in women } \\
\text { in Canada* }\end{array}$} \\
\hline True & $206(48.5)$ & $304(55.5)$ & $510(52.4)$ \\
\hline False & I75 (4I.2) & $207(37.8)$ & $382(39.3)$ \\
\hline Don't know & $44(10.4)$ & $37(6.8)$ & $81(8.3)$ \\
\hline \multicolumn{4}{|c|}{$\begin{array}{l}\text { Question 3: Heart disease most } \\
\text { common cause of death in men } \\
\text { in Canada }\end{array}$} \\
\hline True & $324(76.2)$ & $403(73.5)$ & 727 (74.7) \\
\hline False & 77 (18.1) & 95 (I7.3) & $172(17.7)$ \\
\hline Don't know & $24(5.6)$ & $50(9.1)$ & $74(7.6)$ \\
\hline
\end{tabular}

Notes: ${ }^{\phi}$ The gender variable was missing for three participants thus the results reported in this table are based on $n=973$, rather than $n=976 ; * p<0.05$.

(11.4\% and $19.4 \%$, respectively) compared with the other ethnic categories. See Table 4 for more details.

\section{Other variables}

Education, income, and AMI history in self, family or friend were not found to be associated with the answers to Questions 1 and 3.

\section{Multivariate analysis}

Interactions of ethnicity with age and with gender were not significant for both outcomes. AMI history in self, family or friend was found to have a high $\mathrm{p}$ value in the likelihood ratio tests indicating it did not have high explanatory power, thus it was excluded from the model. For the outcomes for Question 1 (knowing that heart disease is the most common cause of death in women, individuals who responded 'False' were more likely to be Chinese. Individuals who responded 'Don't know' were more likely to be Chinese or South Asian, male and have lower educational attainment. With regard to Question 3 (heart disease is the most common cause of death in men in Canada), none of the explanatory variables was found to be significant for individuals who responded 'False'. Individuals who responded 'Don't know' to this question were more likely to be female as well as belong to the South Asian or Chinese community (see Table 5).

\section{Discussion}

Compared with other research investigating perceptions of women's risk of heart disease mortality, this study included both men and women; thus, it was possible to investigate gender differences in risk perception (not only regarding what people think about their own risk, but also the risk for the other gender). Overall, far fewer respondents recognized the risk posed to women than to men (52.4\% and $74.7 \%$, respectively). Most noteworthy, we found gender differences with each gender being more likely not to know the answer regarding the risk of heart disease for the opposite gender. Women were 1.8 times more likely than men to answer that they did not know if heart disease was the most common cause of death for men and, conversely, men were 1.8 times more likely than women to answer that they did not know about women's risk. This is an interesting finding given that researchers tend to conclude that women mistakenly underestimate their risk, however they fail to contrast men's perceptions of women's risk of heart disease mortality and vice versa.

This study also found that there were significant ethnic differences in the participants' understanding of the risk of heart disease mortality in women and men. South Asian-Canadian immigrants and Chinese-Canadian immigrants were significantly more likely to indicate that they did not know whether heart disease is the leading cause of death for men and women. The Chinese-Canadian immigrants were also significantly more likely to respond 'False' to the statement that heart disease was the most common cause of death for women. It is interesting that no other variable but ethnicity was found to be statistically significant in the multivariate model for the most common cause of death for women when comparing those who responded 'False' to those who responded 'True'.

An advantage to this study is that the survey was administered in four languages, thus it included individuals who are often excluded from survey research because of language barriers. It is also the only study to our knowledge that investigated this issue in a Canadian sample, where ethnic 


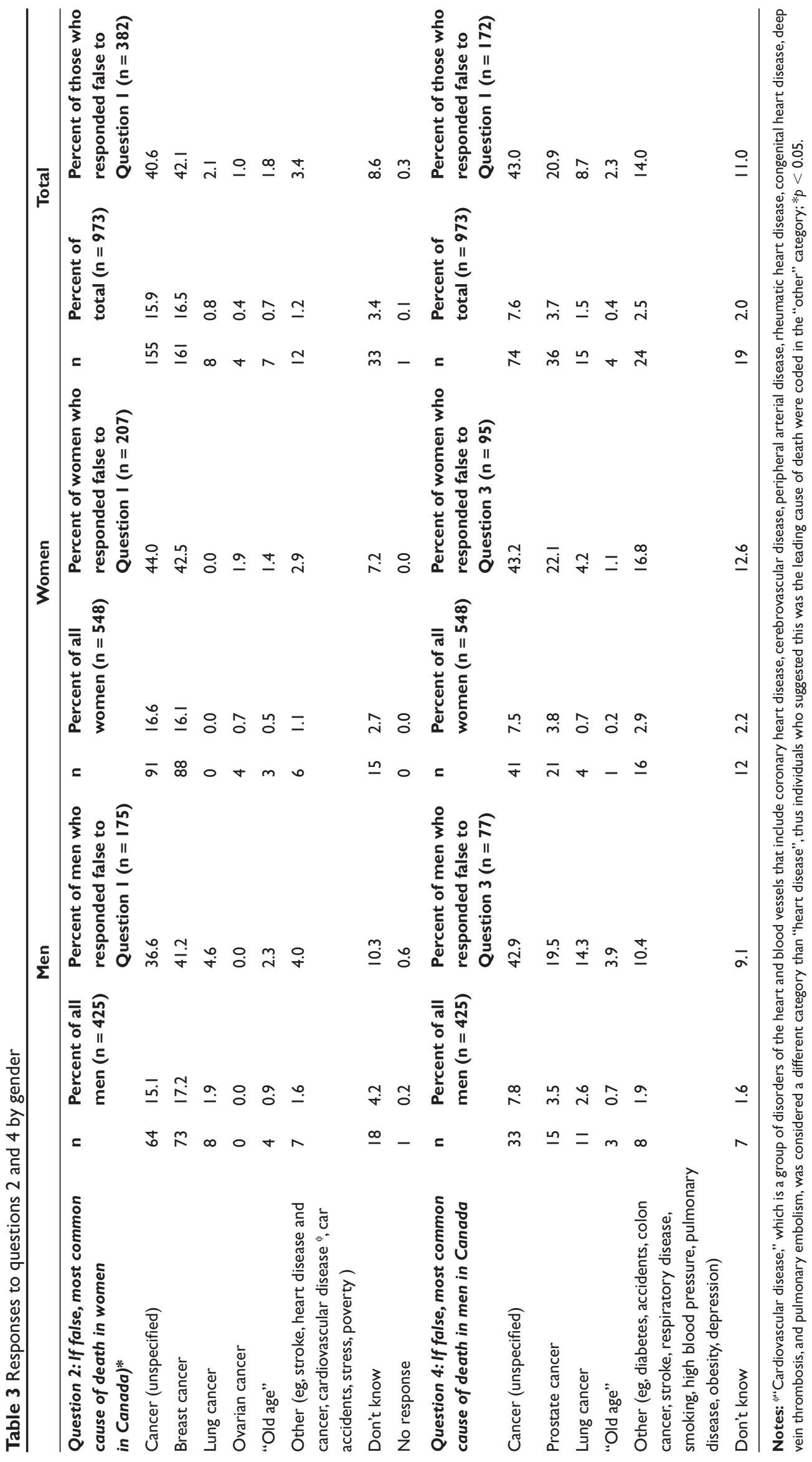




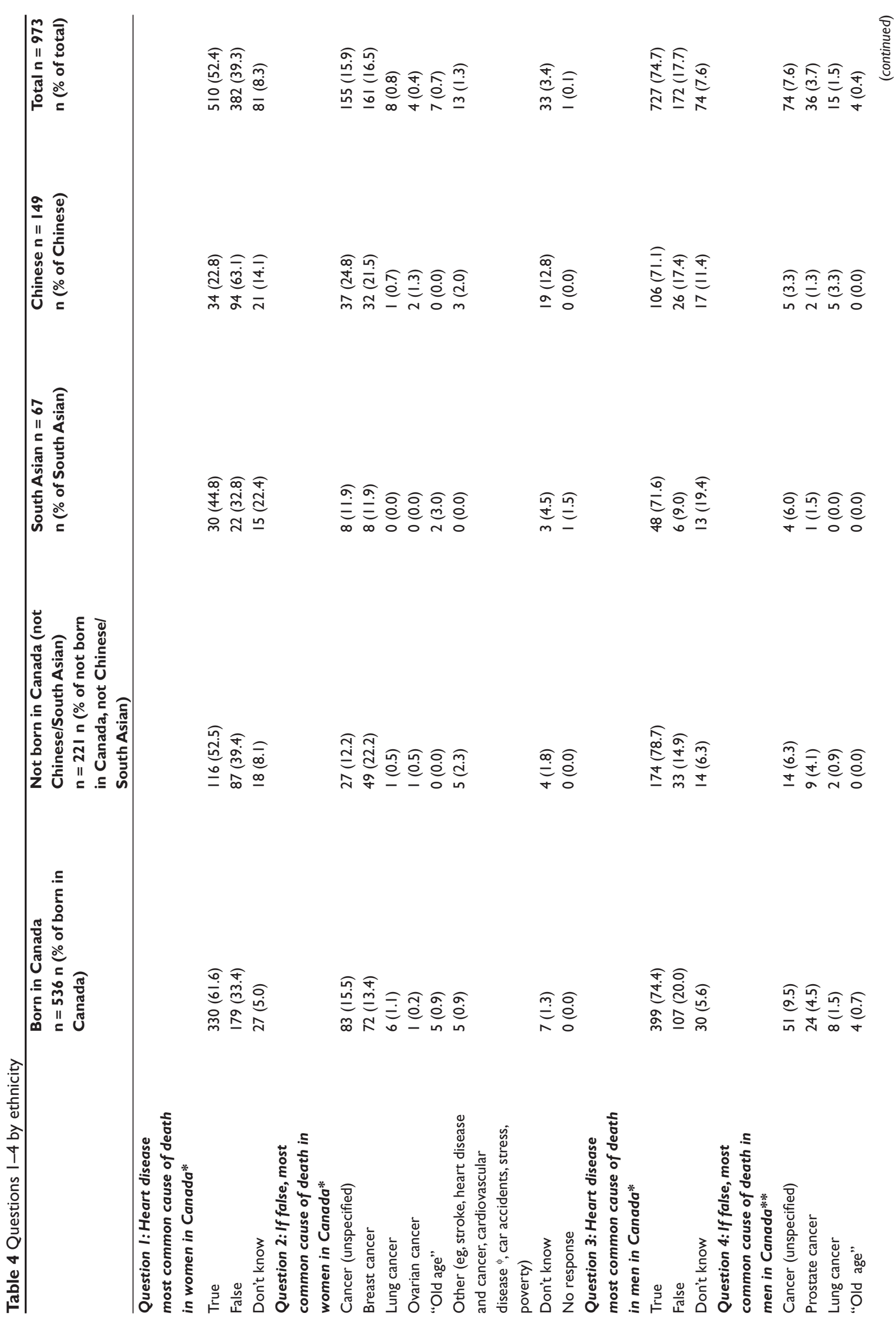




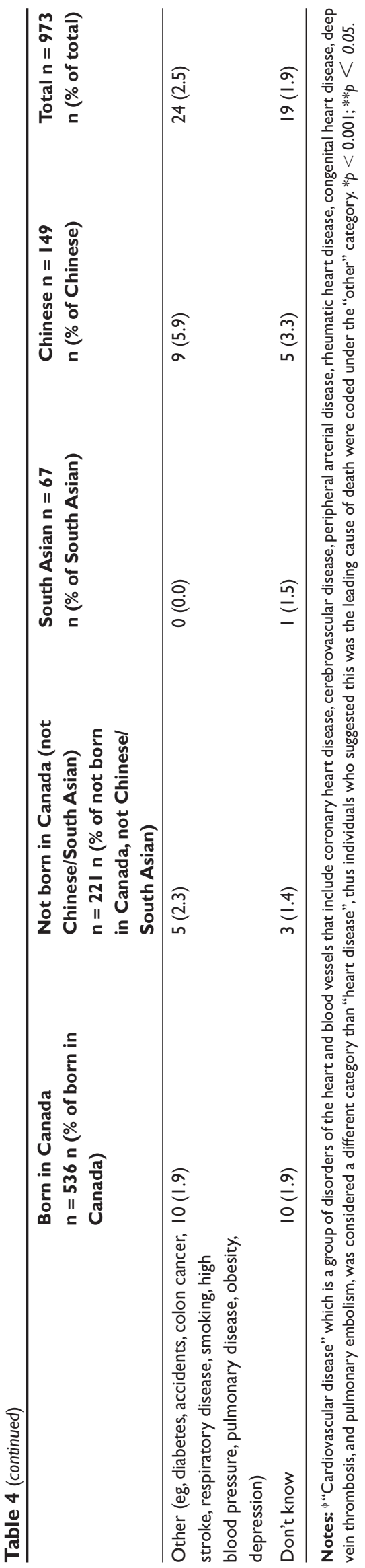

diversity is different than that observed in other countries, such as the USA, where most of the studies to date have been conducted.

Of interest are the responses to the question regarding the most common cause of death in women (if not believed to be heart disease). Most of the women who reported that heart disease was not the leading cause of death believed that cancer (unspecified) was the most common cause of death, and almost as many believed that breast cancer specifically was the most common cause of death. None of the women mentioned lung cancer even though the age-standardized mortality rate of neoplasms of the trachea, bronchus and lung is higher than that of malignant neoplasms of the breast (Statistics Canada 2004b). Similar results were found for the men, although most believed that the most common cause of death for women was breast cancer, and a small percentage responded that it was lung cancer. For men's risk of mortality, more than twice as many participants (men and women combined) believed that prostate cancer was the leading cause of death, rather than lung cancer, although the age-standardized mortality rate for malignant neoplasms of the trachea, bronchus, and lung in 2004, was more than twice that of prostate cancer (Statistics Canada 2004b). Awareness and education regarding the risk of lung cancer in men and women should be made a public health priority.

A limitation of this study is that the questions posed to the participants may have been somewhat vague or leading. When a participant is faced with the statement, 'Heart disease is the most common cause of death in women/men in Canada' they likely try to think of other causes of death and assess whether they think heart disease claims more lives. However, those other causes of death could be general such as 'all cancers' or specific, such as 'breast cancer'. The choice of comparator is crucial because when comparing the rate of all malignant neoplasms to 'diseases of the heart', malignant neoplasms are the leading cause of death in Canada for women, men, and men and women combined. However, cardiovascular disease as a group is responsible for more deaths than malignant neoplasms, and specifically diseases of the heart are responsible for more deaths than any single type of cancer or any other single cause of death. The ranking of a preselected list of causes of death may be a more appropriate method of assessing the perceptions of mortality risk. Another alternative is an open ended question, "What is the leading cause of death for all women/men?" as done in the American Heart Association National Study (Mosca et al 2004). Then, interviewers could be instructed to probe participants if their responses are not specific 
Table 5 Multivariate multinomial logistic regression for 'False' and 'Don't know' responders versus 'True' responders to Question I and Question 3

\begin{tabular}{|c|c|c|c|c|c|}
\hline Variable & Category & $\begin{array}{l}\text { Heart disease is the } \\
\text { most common cause } \\
\text { of death in women in } \\
\text { Canada ("true") Odds } \\
\text { ratio }(95 \% \mathrm{Cl})\end{array}$ & & $\begin{array}{l}\text { Heart disease is the } \\
\text { most common cause } \\
\text { of death in men in } \\
\text { Canada ("true") } \\
\text { Odds ratio }(95 \% \mathrm{Cl})\end{array}$ & \\
\hline & & $\mathrm{FALSE}^{\delta}$ & DON'T KNOW ${ }^{\delta}$ & $\mathrm{FALSE}^{\delta}$ & DON'T KNOW ${ }^{\delta}$ \\
\hline Age & & $\mathrm{I} .00$ (0.99 to I.02) & 1.03 (I.00 to I.05)* & $\mathrm{I} .00$ (0.99 to I.02) & 1.02 (I.00 to 1.05$)$ \\
\hline \multirow{2}{*}{$\begin{array}{l}\text { Gender of } \\
\text { respondent }\end{array}$} & Male & 1.00 & 1.00 & 1.00 & 1.00 \\
\hline & Female & 0.79 (0.59 to I.05) & 0.55 (0.33 to 0.92$)^{*}$ & $\mathrm{I} .02(0.72$ to I.44) & $1.77(\mathrm{I} .04 \text { to } 3.0 \mathrm{I})^{*}$ \\
\hline \multirow[t]{4}{*}{ Education } & $<$ High school & 1.00 & 1.00 & 1.00 & 1.00 \\
\hline & High school complete & 0.97 (0.54 to I.74) & $0.23(0.10 \text { to } 0.53)^{* *}$ & 1.08 (0.55 to 2.15$)$ & 0.47 (0.20 to I.08) \\
\hline & $\begin{array}{l}\text { College/diploma/ } \\
\text { certificate/ incomplete } \\
\text { university }\end{array}$ & I.IO (0.6I to I.98) & $0.40(0.18 \text { to } 0.90)^{*}$ & 0.87 (0.44 to I.75) & $0.6 \mathrm{I}$ (0.27 to I.42) \\
\hline & Baccalaureate or higher & 0.97 (0.53 to I.77) & $0.43(0.19 \text { to } 0.97)^{*}$ & 0.73 (0.36 to I.49) & 0.70 (0.30 to I.63) \\
\hline \multirow[t]{6}{*}{ Income ${ }^{\phi}$} & $\$ 0-\$ 19,999$ & 1.00 & 1.00 & 1.00 & 1.00 \\
\hline & $\$ 20,000-\$ 39,999$ & $\mathrm{I} .37(0.75$ to $2.5 \mathrm{I})$ & $1.00(0.43$ to 2.35$)$ & 1.075 (0.53 to 2.18$)$ & I.I5 (0.48 to 2.73$)$ \\
\hline & $\$ 40,000-\$ 59,999$ & 0.80 (0.42 to 1.52$)$ & $0.58(0.27$ to $1.4 \mathrm{I})$ & 0.93 (0.44 to I.97) & 0.68 (0.28 to 1.67$)$ \\
\hline & $\$ 60,000-\$ 79,999$ & I.06 (0.57 to I.95) & 0.84 (0.28 to 2.50$)$ & 0.7 I (0.34 to I.52) & 0.95 (0.25 to 3.62$)$ \\
\hline & $\$ 80,000-\$ 99,999$ & 0.97 (0.53 to I.78) & $0.36(0.10$ to 1.33$)$ & 1.24 (0.60 to 2.57 ) & $0.7 \mathrm{I}(0.22$ to 2.30$)$ \\
\hline & $\$ 100,000+$ & 0.91 (0.48 to I.72) & 0.64 (0.24 to I.75) & $1.26(0.62$ to 2.55$)$ & $0.63(0.21$ to 1.93$)$ \\
\hline \multirow[t]{4}{*}{ Ethnicity } & Born in Canada & 1.00 & 1.00 & 1.00 & 1.00 \\
\hline & $\begin{array}{l}\text { Not born in Canada } \\
\text { (not Chinese/South } \\
\text { Asian) }\end{array}$ & 1.38 (0.98 to I.93) & 1.79 (0.94 to 3.44$)$ & $0.72(0.47$ to I.I2) & $1.00(0.5 \mathrm{I}$ to $\mathrm{I} .96)$ \\
\hline & $\begin{array}{l}\text { South Asian (not born } \\
\text { in Canada) }\end{array}$ & I. 44 (0.78 to 2.65$)$ & 4.08 (I.75 to 9.52$)^{* *}$ & $0.47(0.19$ to I.16) & $2.99(1.34 \text { to } 6.66)^{* *}$ \\
\hline & $\begin{array}{l}\text { Chinese (not born in } \\
\text { Canada) }\end{array}$ & 5.37 (3.38 to 8.53$)^{* * * *}$ & 7.53 (3.63 to I5.63)*** & $0.96(0.58$ to 1.60$)$ & $2.06(1.03 \text { to } 4.11)^{*}$ \\
\hline
\end{tabular}

Notes: ${ }^{\delta}$ The referent is 'True’; ${ }^{M}$ Multiple imputations of values for missing data for income were used; ${ }^{*} p<0.05 ; *^{*} p<0.01 ; *^{* * *} p<0.001$.

(eg, 'heart disease' or 'cancer') to ensure that it is understood what is meant. This open-ended question was presented in our study (Questions 2 and 4), however only to those who said 'False' to the question, "Heart disease is the leading cause of death in women/men." Results obtained from this open-ended question combined with the question specifically about heart disease (Questions 1 and 3) may be different from results obtained solely from an open-ended question. As described by Waller and colleagues (2004), in the context of measuring knowledge about cancer, unprompted recall and prompted recall give different results with unprompted recall indicating a much lower level of knowledge than prompted recall. It is possible that given the format of the question regarding heart disease, the study results slightly overestimate the knowledge in this sample compared with results that would have been obtained from unprompted recall.
Another limitation of this study was the response rate, ranging between $28.5 \%$ and $56.3 \%$ (see Results section for details). Nonetheless, the sample characteristics are comparable to the Vancouver population, based on the 2001 Census (Statistics Canada 2001). For example, our sample included $15.3 \%$ individuals classified as Chinese, compared with $16.6 \%$ found in the Census. Similarly, our sample included $6.9 \%$ South Asian people, compared with $6.2 \%$ found in the Census. Our sample does include too few individuals with less than high school education and reported household income of less than $\$ 20,000$; these are people often underrepresented in survey research.

The general public still conceives of heart disease as primarily a health problem for men, and in some studies, researchers have found that women believe that they are at greater risk of breast cancer mortality than of heart disease 
mortality (Hart 2005). This study showed that there is still a discrepancy between the actual and perceived risk of heart disease for women (held by both men and women), a discrepancy that is especially profound in the Chinese and South Asian immigrant populations. There is a need to educate these communities about the risks of heart disease as a first step in promoting health behavior change. As described by Green and Kreuter (1999), an important component of health promotion programs aimed at bringing about behavioral change are predisposing factors, such as a person's or population's knowledge, attitudes, beliefs, values and perceptions. These play an important role in facilitating or hindering motivation for change and should be addressed when targeting a public health issue. Further, when the public's perceptions of risk or need are not in accordance with those of epidemiologists and other professions within the health sector, the priorities set (and resources expended) by policy makers may be influenced by factors other than scientific evidence (Green and Kreuter 1999).

Women's and men's perception of the opposite gender's risk of heart disease can greatly influence their decision-making process with regard to healthcare decisions and health behavior (Hart 2005). Misperceptions may lead people to underestimate their own risk for heart disease and fail to seek early intervention to prevent unnecessary morbidity and mortality (Hart 2005). Heart disease is largely preventable and many heart disease risk factors may be managed through lifestyle modification. Public education directed at altering personal behavior remains the most effective strategy for reducing disease risk (Collins et al 2004). Women will need to see themselves as vulnerable to heart disease before they will be willing to adopt measures to prevent it (Pilote and Hlatky 1995), and men will need to see the women in their lives as vulnerable to heart disease to help them take action to prevent it. Also, if women do believe that heart disease is a threat, they often view it as something to worry about later in life, which effectively undermines prevention efforts. This dangerous lack of awareness in women needs to be seen as a call to action for women and health care professionals (Robertson 2001). Because resources for health promotion and disease prevention are limited, prioritizing is crucial (Green and Kreuter 1999). The findings of this study suggest that the South Asian and Chinese-Canadian communities should be especially targeted for health promotion messages regarding the risk of heart disease in women.

\section{Acknowledgments}

This research was supported by a grant from the Canadian Institutes of Health Research and infrastructure support from the Michael Smith Foundation for Health Research (MSFHR). The authors acknowledge grant support from the
Canadian Institutes of Health Research (CIHR) (MOP-53065).

Dr Grunau acknowledges GENESIS for post-doctoral training support. Dr Ratner holds a MSFHR Senior Scholar award.

\section{References}

[AHA] American Heart Association. 2008. Women and cardiovascular disease - Statistics [online]. Accessed January 31, 2008. URL: http://www.americanheart.org/downloadable/heart/ 1199816973854FS10WM08.pdf.

Collins KM, Dantico M, Shearer NBC, et al. 2004. Heart disease awareness among college students. J Community Health, 29:405-20.

Green LW, Kreuter MW. 1999. Health promotion planning : an educational and ecological approach. Mountain View, CA:Mayfield Pub. Co.

Hammond J, Salamonson Y, Davidson P, et al. 2007. Why do women underestimate the risk of cardiac disease? A literature review. Aust Crit Care, 20:53-9.

Hart PL. 2005. Women's perceptions of coronary heart disease: an integrative review. $J$ Cardiovasc Nurs, 20:170-6.

Krenten-Boaretto B, Buxton J, Dore K, et al. 2003. Using provincial client registries for selection of control subjects: lessons learned. Can Commun Dis Rep, 29:173-9.

Legato MJ, Padus E, Slaughter E. 1997. Women's perceptions of their general health, with special reference to their risk of coronary artery disease: results of a national telephone survey. $J$ Womens Health, 6:189-98.

Miller CL, Kollauf CR. 2002. Evolution of information on women and heart disease 1957-2000: a review of archival records and secular literature. Heart Lung, 31:253-61.

Mosca L, Ferris A, Fabunmi R, et al. 2004. Tracking women's awareness of heart disease: an American Heart Association national study. Circulation, 109:573-9.

Mosca L, Jones WK, King KB, et al. 2000. Awareness, perception, and knowledge of heart disease risk and prevention among women in the United States. American Heart Association Women's Heart Disease and Stroke Campaign Task Force. Arch Fam Med, 9:506-15.

Mosca L, Linfante AH, Benjamin EJ, et al. 2005. National study of physician awareness and adherence to cardiovascular disease prevention guidelines. Circulation, 111:499-510.

Pilote L, Hlatky MA. 1995. Attitudes of women toward hormone therapy and prevention of heart disease. Am Heart J, 129:1237-8.

Ratner PA, Johnson JL, Mackay M, et al. 2008. Knowledge of "heart attack" symptoms in a Canadian urban community. Clinical Medicine: Cardiology, 2:201-13.

Ratner PA, Tzianetas R, Tu, AW, et al. 2006. Myocardial infarction symptom recognition by the lay public: the role of gender and ethnicity. $J$ Epidemiol Community Health, 60:606-15.

Robertson RM. 2001. Women and cardiovascular disease: the risks of misperception and the need for action. Circulation, 103:2318-20.

Slovic P. 2001. The risk game. J Hazard Mater, 86:17-24.

Statistics Canada. 2001. Basic cross-tabulations, Census 2001 [online]. Accessed June 23, 2008. URL: http://www12.statcan.ca/english/ census $01 /$ products $/$ standard $/$ themes $/$ Index.cfm? Temporal $=$ 2001\&APATH $=3 \&$ FREE $=0$.

Statistics Canada. 2004a. Community profiles 2001 Census of Canada. Ottawa, Statistics Canada [online]. Accessed June 10, 2008. URL: http://www12.statcan.ca/english/Profil01/CP01/Index.cfm?Lang = E.

Statistics Canada. 2004b. Table 102-05511 Deaths, by selected grouped causes, age group and sex, Canada, provinces and territories, annual [online]. Accessed January 31, 2008. URL: http://cansim2.statcan. ca/cgi-win/CNSMCGI.PGM.

Waller J, McCaffery K, Wardle J. 2004. Measuring cancer knowledge: comparing prompted and unprompted recall. Br J Psychol, 95:219-34.

[WHO] World Health Organization. 2008. Cardiovascular disease [online]. Accessed January 31, 2008. URL: http://www.who.int/ cardiovascular_diseases/en/. 